\title{
A EQUIPE DE ENFERMAGEM
}

\section{Haydée Guanais Dourado (*) Ivaneyde Dourado Costa (**)}

\section{INTRODUÇAOO}

E fora de dúvida que as enfermeiras, no mundo inteiro, recomendam que seja contínuamente analisada a faixa de atribuições de cada ocupação de enfermagem. ( $\left.{ }^{1}\right)$

No Relatório da Comissão de Peritos em Ensino de Enfermagem, da OMS, que se reuniu em Genebra, em 1953, com a participação da Dra. Glete de Ancântra, está contido o seguinte: "no país em que a evolução da enfermagem se encontra nos primeiros estágios, a formação básica profissional da enfermeira incluirá preparo para ensino e supervisão. Ao desenvolver-se mais, a assistência de enfermagem e a relação enfermeira/paciente receberão maior ênfase na formação da enfermeira".

Em suma, continuamente devemos analisar e corrigir as faixas de funções de todas as ocupações de enfermagem. A enfermeira está se tornando cada vez mais um profissional que atende o cliente.

\section{A EQUIPE DE ENFERMAGEM}

Para utilizar-se o pessoal de enfermagem com o máximo de economia e eficiência tem sido demonstrado $\left(^{2}\right)$ que o cuidado centralizado no paciente dado por equipe de enfermagem é a melhor perspectiva.

Por equipe entende-se um grupo social, unido por um objetivo comum, em que cada um deve saber o papel a executar, deve estar

(*) Enfermeira, Centro de Estudos, Fundação Hospitalar do Distrito Federal.

(**) Enfermeira responsável, Unidade de Pediatria Cirúrgica, 1.0 Hospital Distrital de Brasilia. 
familiarizado com as regras do funcionamento da equipe e, voluntariamente, aceitar a direção do líder.

REQUISITOS LEGAIS E CARACTERISTICAS ESSENCIAIS DOS PARTICIPANTES DA EQUIPE DE ENFERMAGEM

Exemplo de membros da equipe de enfermagem para um hospital brasileiro: enfermeira chefe da unidade, enfermeira líder da equipe, técnicos de enfermagem, auxiliares de enfermagem e atendentes.

\section{REQUISITOS LEGAIS}

Os exercentes de enfermagem - enfermeira, técnico de enfermagem e auxiliar de enfermagem - devem estar decidamente inscritos no órgão fiscalizador competente, de acordo com as leis em vigor. Os atendentes de enfermagem, que não são registrados, prestam também seu concurso útil à equipe.

\section{EXEMPLO DO FUNCIONAMENTO DE EQUIPES DE ENFERMAGEM}

Para esclarecimento de como age uma enfermeira especialistá, no hospital, o seguinte relato mostra pontos que as enfermeíras têm por meta e esperam atingir. Uma enfermeira norte-americana, Catrarine Killourie $\left(^{3}\right)$, bem sucedida em seu trabalho no Centro Médico da Universidade da Califórnia, relata as seguintes condições. São 50 os pacientes das áreas de cirurgia geral e plástica, obstetrícia com complicações e ginecologia. Com a $1 .^{\mathrm{a}}$ assistente (ainda tem uma 2. ${ }^{\text {a }}$ para sua substituição, à tarde), divide, no horário da manhã, ao meio, o total dos 50 pacientes para a responsabilidade de coordenar o diagnóstico das necessidades de enfermagem e o plano individual de cuidado de enfermagem. Todas as enfermeiras, técnicos de enfermagem e estudantes da área dão sugestões.

No horário da manhã (7,30 às 16 horas) há pelo menos ọito enfermeiras outras para 50 pacientes, e esse número é acrescido dos referidos técnicos e estudantes, que se encarregam dos cuidados pessoais ao paciente. Quinzenalmente, os médicos respectivos dos pacientes a serem vistos comparecem às sessões de estudo de enfermagem, explanando seus diagnósticos, tratamento e prognósticos. Totaliza trinta o número de médicos nessa clínica, que é aberta. Continua a descrição da enfermeira, discriminando em seis sub-áreas seu desempenho profissional a saber:

- determina necessidades de pacientes; 
- coordena o cuidado dos pacientes, inclusive prestando sua parte nesse cuidado;

- ministra a educação em serviço ao nível da clínica;

- avalia;

- desempenha a gerência da Unidade de Enfermagem relacionada:

a) com a limpeza, suprimentos e estoques, equipamentos e sua verificação e obtenção da roupa necessária;

b) com a comunicação com a divisão de nutrição.

No dia-a-dia, grande parte de seu tempo é dado para recolher informes e dar relatos aos médicos, além de seu intercâmbio com dirigidos e com a família do paciente, fora o tempo referido para os planos de cuidado de enfermagem.

Terminamos aqui a informação obtida da autora norte-americana. Nós enfermeiras neste país, não nos sentimos solicitadas, como especialistas, na medida em que já somos capazes de contribuir. As causas? Aqui citamos uma: no passado a formação inadequada de um número grande de enfermeiras. Outra causa: é grande a proporção de atendentes (*) em nosso pessoal de enfermagem. o atendente, entre todos os que dão assistência de enfermagem, tem aparecido na proporção incidental de $70 \%$ a $47 \%$. fácil fazer-se a suposição de que os médicos, muitas vezes, achem que não vale a pena contar com o concurso típico de profissionais de nivel superior em seu trabalho como enfermeiras, no hospital. Quando elas são capazes, o médico se interrelaciona muito bem, buscando uma boa contribuição da enfermagem. O que nos ocorre é que talvez houvesse meios de institucionalizar-se melhor essa contribuição. sabido que as próprias enfermeiras realizam menos do que o fariam, se houvesse melhores condições. Em resumo, a reflexão atual de grande número de nossas colegas é que terá que haver enfermeira assistindo cada doente, com a perspectiva da equipe. Isto é, uma enfermeira seria responsável, a princípio por 10 a 20 ou mais pacientes internados, auxiliada por técnicos e auxiliares de enfermagem.

(*) A proporção de atendentes no grupa dos que dão assistência de enfermagem, na Fundação Hospitalar do Distrito Federal, aprovado, para 1974, é de $47,1 \%$ de acordo com dados fornecidos pela Coordenação de Enfermagem. Para o pais como um todo, estudo por amostragem da Associação Brasileira de Enfermagem indicou haver $70 \%$ em 1958 (Relatório do levantamento de Recursos e Necessidades de enfermagem no Brasil). ABEn. 1959 - Mimeogr. 


\section{CARACTERISTICAS ESSENCIAIS DOS PARTICIPANTES DE EQUIPE}

Para constituir equipe, a enfermeira - chefe e as líderes, em decisão conjunta, designam os participantes, em cada período de trabalho, - manhã e tarde.

A líder da equipe, na qualidade de especialista clínica, também dá cuidados diretos aos pacientes.

As caracteristicas essenciais das enfermeiras devem ser: conhecimento, destreza, capacidade e atitude profissional, inclusive compreensão humana. Quanto à sua função, convem recorrer ao que está descrito em cinco itens à p. 26 da obra citada, de Lambertsen.

Sumarizando, uma enfermeira (que poderá ser a enfermeirachefe da unidade ou a líder) é responsável pela formulação escrita do plano, que deve ser por ela assinado. Distinguirá todos os aspectos dos cuidados a serem prestados, e os delegará devidamente. Dirigirá a execução, e em seguida avaliará e registrará os resultados dos cuidados de enfermagem.

Além de agir como especialista, é importante que a líder transmita aos membros da equipe, em seu devido tempo, informações pertinentes ao que se espera de cada um, à maneira de aperfeicoamento da habilitação que todos já possuem. Em nosso país, por se encontrar ainda em desenvolvimento, é de grande oportunidade a enfermeira atuar nesse ensino contínuo. Para todos os membros da equipe, a competência e habilidade no desempenho técnico de suas atribuições é essencial.

Por último, não o últímo em importância, as qualídade éticas e humanas de todos são talvez a chave para o sucesso do trabalho: boa vontade de cada um é o fundamento, uma vez que tudo mais pode ser melhorado e aprendido. O pensamento único; a harmonia e motivação do grupo são essencials.

Adotar a perspectiva de equipe não será difícil, - o importante é exercitar. A prática irá produzindo nossa perícia ou tarimba para passarmos, no Brasil, adotar em todos os bons hospitais o trabalho de equipe.

\section{REFERENCIAS BIBLIOGRAFICAS}

(1) Oficina Internacional del trabajo - Empleo y condiciones de trabajo del personel de enfermeria, Genebra, 1960, p. 183.

(2) LAMOBERTSEN, Eleanor C. - Equipe de Enfermagem - Resultados de um estudo da Divisão de Ensino de Enfermagem, Teachers Colleg, Columbia University, trad. de Aguiar, H. D. Ferrarini, C.D.T. e Outros, Rio de Janeiro, Serviço Especial de Saúde Pública, 1958, 104 p.

(3) KILLOURIE, C. W., Relationship of the head nurse to team nursing. In Hospital Management, Fevereiro 1967, p. 47 a 50. 